\title{
"Learning by Doing": a Mixed-Methods Study to Identify Why Body Painting Can Be a Powerful Approach for Teaching Surface Anatomy to Health Science Students
}

\author{
Claudia M. Diaz ${ }^{1}$ D $\cdot$ Torres Woolley $^{2}$
}

Accepted: 14 August 2021 / Published online: 9 September 2021

(C) International Association of Medical Science Educators 2021

\begin{abstract}
Introduction Teaching human anatomy to produce deeper understandings and knowledge retention in learners requires meaningful, engaging, and practical activities. Previous studies identify that most students who participated in body painting (BP) reported improved understanding of surface anatomy (SA). This study investigates the key factors underpinning how BP helps students learn SA.

Methods The study involved an explanatory mixed-methods approach. Towards the end of an anatomy course, a survey was administered to three cohorts of first-year chiropractic, osteopathy, and Chinese medicine students and second-year biomedical sciences students over 3 years $(n=311$; response rate $=30 \%$ ). The survey assessed the effectiveness of BP as a hands-on, group-based approach for learning SA in practical class. Three student focus groups $(n=13)$ explored the key survey findings. Results Overall, $72 \%$ of student respondents reported BP activities helped them learn SA "quite a bit" or "very much". Multivariate analysis identified students found BP helped them learn SA by "remembering the position of the bones, joints, muscles, actions and insertions" ( $\mathrm{POR}=5.7 ; P<0.001)$; "integrating textbook and other knowledge on a real live person" $(\mathrm{POR}=2.4 ; P=0.027)$; and "achieving a deeper understanding of SA" (POR $=5.2 ; P<0.001)$. The qualitative findings describe specifically how BP helps students learn, understand, and remember SA.

Conclusions The findings show the majority of students believed BP benefitted their learning of SA through enhancing engagement in self-directed classroom and out-of-hours learning opportunities, deeper understandings of form and function, retention of knowledge, and practical physical examination experiences palpating the variations in form between individuals.
\end{abstract}

Keywords Gross anatomy education · Undergraduate education · Health profession education · Body painting · Active learning $\cdot$ Engagement $\cdot$ Learning $\cdot$ Innovation $\cdot$ Surface anatomy

\section{Introduction}

Historically, the use of prosections and cadaver dissection have been the focus of anatomy teaching and learning [1-5]. Although engaging, and beneficial for learning of anatomy, the emphasis on cadaver dissection has changed dramatically over the past 20 years due to decreases in cadaver donations and an increase in student numbers [6]. Even though

Claudia M. Diaz

cdiaz@csu.edu.au

1 School of Dentistry and Medical Sciences, Charles Sturt University, Albury, N.S.W 2640, Australia

2 College of Medicine and Dentistry, James Cook University, Townsville, QLD, Australia the use of human prosections is central to and invaluable for learning anatomy, studies propose it is important that students also concentrate their efforts on surface anatomy [7-10]. Surface anatomy is "visual anatomy" - dealing with anatomical structures on living bodies that can be studied only with sight, such as the form and proportions of the body and surface landmarks that relate to deeper structures [11-13]. Surface anatomy allows students the opportunity to consolidate the anatomy that they have learned using the prosections and relate it to living beings. As future health professionals, students must work on live patients or clients, and so must be able to identify anatomical structures on real bodies [14]. Surface anatomy also teaches students physical examination skills: to observe, examine, and interact with a living person [15] that necessarily involves observation, palpation of bony prominences, muscles, and tendons, and 
the identification of surface projections of bones, muscles, or organs on the body surface or walls. The study of surface anatomy is particularly important in studying the musculoskeletal system, as students can see structures moving and functioning.

More recently, with a reduction in contact hours to teach anatomy [4], there has been a move to complement the use of prosected tissues in the laboratory using multi-disciplinary [16], more pro-active, non-didactic, "hands-on" approaches $[14,17]$. Stimulating, engaging, experiential $[18,19]$, and fun learning approaches appear to produce students who are pro-active, confident, and self-directed learners [14, 17]. This experiential learning includes the use of whiteboards as learning tools, and Play Doh for modelling anatomical structures, movements, and surface anatomy that appear to assist students to experience deeper learning [14, 17]. For example, surface anatomy can easily be undertaken on oneself, classmates, colleagues, family, or friends.

Body painting (BP) has been identified as an effective tool for learning surface anatomy and associated clinical skills $[15,17,20-28]$. BP is a fun teaching and learning approach that is popular among students, as it is an engaging way to learn anatomy by looking, identifying surface landmarks, palpating, drawing, and then painting $[14,17,20]$. BP is a motivating and creative experience for students that provides memorable visual images [21] and encourages multisensory and active participation [14, 17]. While BP is suitable for all students, cultural sensitivity and careful negotiation may be necessary to ensure all students are comfortable carrying out the activities. For example, at a regional Australian medical school (James Cook University), students from many cultures, including Muslim students, were enthusiastic about participating in BP activities and through careful negotiation were able to find areas of the body they were all comfortable to paint $[14,17]$. Students have also reported that they participate in BP activities in their free time with classmates and friends, further supporting this as an engaging learning approach [14, 17].

\section{Introducing Body Painting Activities to Anatomy Curricula in Australia}

BP has become an accepted teaching approach used by medical and health science courses around the world and in Australia [15, 17, 20-28]. From 2010 to 2021, the first author of the present study has included BP as one of several strategies for teaching anatomy at James Cook University (JCU), Royal Melbourne Institute of Technology (RMIT) University, La Trobe University, and Charles Sturt University (CSU). Before BP was included in the curricula, anatomy at these universities was delivered didactically with more individually oriented learning activities in the practical class - disadvantaging and disengaging students who prefer hands-on learning and/or group learning activities. Adding BP to anatomy practical classes was undertaken to cater specifically for the learning styles of these types of students [14, 17]. However, BP is not yet a standard component of Australian anatomy curricula, and there are no studies reporting the mechanisms by which BP assists or improves student learning. Thus, this study used quantitative and qualitative investigations to identify and understand key factors underpinning how BP helps students to learn surface anatomy.

\section{Materials and Methods}

\section{Practical Classes}

The first author's approach to teaching surface anatomy via BP consisted of multi-sensory, "hands-on" learning modelled by the academic staff and tutors during 2-h weekly practical classes. The laboratory was arranged so students worked in groups around a dissection table, with a whiteboard at one end. Students were required to work together to demonstrate that they had a deeper understanding of the structures and relationships during their study of the prosections. After studying the prosections, students were encouraged to move to a separate section of the laboratory setup for experiential learning of surface anatomy using Play Doh for modelling anatomical structures, movements (learning using hand gestures, weights, or hula hoops for example), and BP. Students were trained in BP techniques from week 1 onwards to encourage participation, with guidelines for BP also included in practical class notes. Focus was placed on the "process" of BP rather than the finished product. Students were encouraged to undertake a systematic approach to BP: physical examination involving observation of bony landmarks, form, and proportions, followed by palpation of important landmarks, then the use of whiteboard markers to outline important landmarks (landmarking), then drawing in the origins and insertions, then outlining the important organs, and finally, undertaking the painting itself. Students were encouraged to use different colors and shading to indicate muscles, tendons, and bones.

The first author also ran an annual "Anatomy Cup" competition that encouraged the use of innovative approaches to learn anatomy. This inter-cohort competition consisted of a series of activities including whiteboarding, Play Doh construction, bone identification, and BP. Students spent the semester preparing for this competition and it was a great incentive and driving force to their participation in surface anatomy and BP. 


\section{Study Design and Participants}

This study utilized an explanatory mixed-methods design. The development of the BP activities has been ongoing at four Australian Universities over 11 years. The data used in this study was collected at RMIT University from three successive cohorts of health science students, involving first-year chiropractic, osteopathy, and Chinese medicine students, and second-year biomedical science students. The self-administered survey on student perceptions of the BP approach was delivered after the final anatomy lecture. The researchers explained the study as the surveys were administered to the students via online information sheets and in person. Analysis of the survey data allowed the major factors to be identified for how BP helps students to learn surface anatomy, and these key factors were later investigated in the qualitative component involving three focus groups - one each for students from biomedical science, Chinese medicine, and chiropractic and osteopathy disciplines. The qualitative component utilized a basic descriptive design [29] to produce simple context-sensitive summaries of students' experiences with BP. This approach allowed in-depth exploration of how BP activities helped student participants learn surface anatomy. This research was approved by the RMIT Human Ethics Committee (ASEHAPP 16-13). In addition, students were asked to sign a media release form in week 1 to allow researchers to use photographs.

\section{Survey}

The survey collected data on demographics (age, gender) and variables known to predict student engagement in BP, such as enjoyment, quality of learning experiences, relevance to future student years and career, active involvement in BP activities, class bonding, and overall level of interaction with teachers/tutors [30-32], with students rating each variable across a scale of 1 to 10 (with 1 being the lowest and 10 being the highest). Students were also asked to rate, across a 4-category Likert scale ("not at all", "a little bit", "quite a bit", "very much"), how much BP helped them learn anatomy, assist their long-term memory of human anatomy, assist their deeper understanding of human anatomy, identify the position of bones, muscles and their origins, learn the muscles and other structural anatomy, inspired/motivated them to learn anatomy, etc. The surveys were administered in the final week of lectures to allow students to more accurately self-assess how well the BP activities had assisted their recall and learning of anatomy, both week-to-week over the semester and in the lead up to studying for their final exams. A full list of the variables as they appeared in the survey is provided in Table 1 .

\section{Focus Groups}

Three separate focus groups were held with RMIT University students of Chinese medicine (1 male, 1 female), biomedical science (1 male, 3 females), and chiropractic and osteopathy (4 males, 3 females). Discussions were conducted by the coauthor TW (JCU medical school academic having no role with the RMIT program). All participants were considered to be information-rich cases that allowed the research questions to be adequately explored [33].

\section{Data Analysis}

Survey data were coded numerically and entered into SPSS release 19 for Windows. Table 1 describes numerical variables as mean values and standard deviations, while categorical variables are described as frequencies. Binary logistic regression analysis (Table 2) identified independent predictors of why RMIT health science students believed BP helped them to learn anatomy "quite a bit"/ "very much", and estimated their strength of association. All engagement variables listed in Table 1 were considered in the multivariate logistic regression analysis, but only independent significant predictors were accepted into the final model. Results of the multivariate logistic regression analysis are presented as prevalence odds ratios (POR) together with 95\% confidence intervals (95\%-CI). POR gives an estimation of relative risk with fewer assumptions than are required for prevalence ratio analyses, and are the generally accepted measure of association used in cross-sectional studies to assess the strength of the relationship between study factor and outcome [34]. Throughout the study, a statistical test was considered significant when $P<0.05$.

Analysis of the qualitative interview data involved digitally recording the discussions and then transcribing a summary of the conversation into a Microsoft Word document. Electronic summaries of the interview were read repeatedly to develop a high level of familiarity with the data (immersion), and then summarized by manually coding into recurrent themes. This thematic analysis was conducted by the author TW, and later checked by CD for investigator triangulation; differences were resolved through discussion between the authors. The sample size in the study was sufficient to allow a "theory-saturation point" to be reached, where new discussions no longer produced new information [33]. Quotes that captured the concepts held by a number of participants were included (Tables 3 and 4).

\section{Results}

Participation in BP activities in the laboratory was always optional and never obligatory, though most students participated willingly (Fig. 1). The first author taught the BP 
Table 1 Self-reported engagement and learning of 311 Royal Melbourne Institute of Technology health science students from participating in body painting (BP) activities associated with surface anat- omy. Students rated each variable across a scale of 1 to 10 (with 1 being the lowest and 10 being the highest)

\section{Body painting variables}

Frequency for categorical variables or mean and standard deviation for numerical variables

I prefer 'hands-on' learning activities or 'no preference' over learning from 'didactic teaching' (rating from 1 to 7 , with 4 being 'no preference')

I prefer 'group-based' learning activities or 'no preference' over learning from 'individual-based' learning activities (rating from 1 to 7 , with 4 being 'no preference')

Enjoyment from participating in BP learning activities (rating from 1-10)

Quality of learning experiences from BP learning activities (from 1-10)

Relevance of BP to later years of course and future career (from 1-10)

Level of active involvement in BP learning activities (from 1-10)

Sense of accomplishment from completing BP learning activities (from 1-10)

Level of interaction and discussion with peers and staff during BP activities (from 1-10)

BP activities helped in bonding the class closer together 'quite a bit/'very much'

$\mathrm{BP}$ activities were enjoyable 'quite a bit/'very much'

BP inspired /motivated me to learn Anatomy 'quite a bit/'very much'

BP helped me to learn Anatomy 'quite a bit/'very much'

BP helped me to integrate textbook and other knowledge on a real live person 'quite a bit/'very much'

BP assisted my deeper understanding of Anatomy 'quite a bit/'very much'

BP assisted my long-term memory of Anatomy 'quite a bit/'very much'

BP helped me to identify the position of bones, joints, muscles and their origins 'quite a bit/'very much'

BP helped me to remember the position of bones, joints, muscles, actions and insertions" "quite a bit/'very much'

BP activities made it easier to learn muscles and other structural Anatomy than from textbooks 'quite a bit/'very much'

$79 \%$
$70 \%$
$7.1 \pm 2.3$
$7.0 \pm 2.2$
$6.8 \pm 2.2$
$6.2 \pm 2.6$
$6.9 \pm 2.1$
$7.8 \pm 1.9$
$69 \%$
$77 \%$
$68 \%$
$72 \%$
$77 \%$
$75 \%$
$75 \%$
$76 \%$
$76 \%$
$69 \%$

process in a way that encouraged students to participate without requiring advanced artistic abilities (Fig. 1). Most anatomy learning occurred during the landmarking phase of the BP process (Fig. 1A, B), which was then followed by the BP using paints and paintbrushes (Fig. 1C-E). Students from different cultural backgrounds were also keen to participate, and their involvement was achieved by negotiating which parts of the body were acceptable for painting (Fig. 1E). BP was an approach able to be used by any student to learn anatomy, with students consolidating what they learn with prosections by looking at the surface anatomy relevant to the area on themselves and each other, and often after class on family and friends.

Students worked in groups for BP, and the activities promoted peer interactions and class bonding (Fig. 2A, C). Students alternated their roles as models, artists, or general helpers (holding atlas pictures, providing paints and supplies). As the final step, the BP work carried out by health and biomedical science students in years 1 and 2 was photographed and uploaded weekly onto a Facebook page called "Innovative Anatomy" (https://www.facebook. com/Innovative-Anatomy-179607045387194). This page allowed the work done by students in practical classes to be shared and used by all students for their study. BP was a popular approach to learning anatomy not only with university students, but also by professionals in the health and funeral industries. The Innovative Anatomy Facebook page has followers all over the world, and media coverage of the body painting resulted in this work being presented to external groups such as radiographers and other specialists from the local hospital (Fig. 2B), and to conferences of the British Institute of Embalmers, and the Australian Institute of Embalmer's from 2012 to 2019 (Fig. 2D, E).

Three hundred and eleven (311) health science students across years 1 and 2 responded to the end of year surveys over 3 years (overall response rate $=30 \%$ ): cohort 1 $n=95 / 364$; cohort $2 n=106 / 352$; and cohort $3 n=110 / 354$. Health science students had a mean age of 21 years $( \pm 5)$, with $188(61 \%)$ being female. Overall, $72 \%$ of health science students reported BP activities helped them learn surface 
Table 2 Results of multivariate logistic regression analysis identifying the factors which predict Royal Melbourne Institute of Technology health science students $(n=303)$ believing body painting (BP) helped them "quite a bit"/ "very much" to learn anatomy

\begin{tabular}{|c|c|c|c|c|}
\hline Predictors & $\begin{array}{l}\text { Sample } \\
\left(n=\mathbf{3 0 3}^{\#}\right)\end{array}$ & $\begin{array}{l}\text { BP helped me to } \\
\text { learn anatomy } \\
(218,72 \%)\end{array}$ & $\begin{array}{l}\text { POR } \\
\text { [95\%-C.I.] }\end{array}$ & $P$-value \\
\hline $\begin{array}{l}\text { BP helps to integrate textbook and other knowledge onto a real live person } \\
\text { Not at all/Only a little } \\
\text { Quite a bit/Very much }\end{array}$ & $\begin{array}{l}69 \\
234\end{array}$ & $\begin{array}{l}24(35 \%) \\
194(83 \%)\end{array}$ & $2.4[1.1-5.2]$ & 0.027 \\
\hline $\begin{array}{l}\text { BP assists deeper understanding of anatomy } \\
\text { Not at all/Only a little } \\
\text { Quite a bit/Very much }\end{array}$ & $\begin{array}{l}76 \\
227\end{array}$ & $\begin{array}{l}23(30 \%) \\
195(86 \%)\end{array}$ & $5.2[2.5-10.9]$ & $<0.001$ \\
\hline $\begin{array}{l}\text { BP helps to learn and remember the position of the bones, joints, muscles, } \\
\text { and insertions } \\
\text { Not at all/Only a little } \\
\text { Quite a bit/Very much }\end{array}$ & $\begin{array}{l}72 \\
231\end{array}$ & $\begin{array}{l}21(29 \%) \\
197(85 \%)\end{array}$ & $5.7[2.8-11.7]$ & $<0.001$ \\
\hline
\end{tabular}

POR [95\%-C.I.] prevalence odds ratio [95\%-confidence interval]

\#Only data of health science students with no missing values for all predictors accepted into the model were analyzed (8 students had missing data from the total of 311 students)

anatomy "quite a bit" or "very much". The multivariate analysis identified the independent predictors for why students thought BP was a significant help for them in learning anatomy: "helped me to remember the position of the bones, joints, muscles, actions and insertions" (POR=5.7;

Table 3 Summary of themes and comments made in three focus groups of Royal Melbourne Institute of Technology health science students $(n=13)$ about the benefits of body painting activities in
$P<0.001)$; "helped me to integrate textbook and other knowledge on a real live person" (POR $=2.4 ; P=0.027)$; "assists your deeper understanding of Anatomy" (POR = 5.2; $P<0.001$ ) (Table 2).

motivating them to learn, better understand, and remember clinically relevant surface anatomy

\begin{tabular}{|c|c|c|}
\hline $\begin{array}{l}\text { Learning } \\
\text { strategy }\end{array}$ & Why this learning strategy works & Learning outcomes for students \\
\hline $\begin{array}{l}\text { Group-based, } \\
\text { self- } \\
\text { directed } \\
\text { learning } \\
\text { approach } \\
\text { supported } \\
\text { by tutors } \\
\text { and the } \\
\text { lecturer }\end{array}$ & $\begin{array}{l}\text { More focused, collegial and engaging interactions with tutors and lecturers } \\
\text { Better communication-you're asking more questions to tutors, lecturers or } \\
\text { fellow students. And not only are you communicating but you're working } \\
\text { towards something (male Osteopathy student) } \\
\text { Some people may be a bit intimidated by it, having to go up and ask a tutor for } \\
\text { help but when you're BP you look at where it goes and it's not as intimidat- } \\
\text { ing. It's a more friendly open line of communication (female Chiropractic } \\
\text { student) } \\
\text { I think it [BP] did create a real fun element in the room though, there was a } \\
\text { lot of laughing and a lot of encouragement, especially when we got towards } \\
\text { the middle of the semester and the next half people were saying, come on, } \\
\text { it's your turn to be BPed, come on have a go, it had really developed a big } \\
\text { comradery sort of feel (female Chiropractic student) } \\
\text { Students 'learn how to learn' } \\
\text { Self-directed study I think really helps for first and second year students. I've } \\
\text { learned ways now, methods to learn (male Biomedicine student) } \\
\text { It's really self-directed learning. It's not them holding your hand telling you } \\
\text { to do this and this and this. She'll literally sit in there and she'll talk to you, } \\
\text { she'll help you but it's all on you. You can sit there and do nothing the whole } \\
\text { practical. If you want, you could go-no skin off her bones if you do go } \\
\text { (female Biomedicine student) }\end{array}$ & $\begin{array}{l}\text { Learning with other students and tutors helps to identify and confirm the } \\
\text { correct anatomy knowledge } \\
\text { It's also very good for both sides, not only the person getting painted but } \\
\text { also the person painting. To paint the other person they need to know this } \\
\text { muscle is over here, there, there, there, so supplementary knowledge. And } \\
\text { the one getting painted, "oh, so that's where it is, I thought it was actually } \\
\text { there". There's more interaction, it's better than just sitting around (male } \\
\text { Osteopathy student) } \\
\text { It helps you learn how to work together as a group. One thing I really learned, } \\
\text { its hard sitting on your own, you don't have anybody to go "hey is one plus } \\
\text { one really one? Two. You know it's like double checking and you know } \\
\text { you are not just learning for you, you're learning for both of you. You're } \\
\text { making sure that both of you, or however many are in the group understand. } \\
\text { I remember I worked with a guy and it was on the nerves of the arm, and } \\
\text { I was having a really hard time of it and I was sitting there asking him the } \\
\text { same question over and over again. What does this mean? What is the BCC? } \\
\text { It was nice having other people around, I wasn't the only one that didn't } \\
\text { understand it. You know having someone else talk it through with you, } \\
\text { physically show you it, it really helped. I'm always basically hey do you } \\
\text { want to study with me now. We're probably going to be here all day looking } \\
\text { at the stuff, body painting. It helps you learn, how to learn with other people } \\
\text { (female Biomedicine student) } \\
\text { Students more strongly engage with Anatomy course content/ more } \\
\text { motivated to learn } \\
\text { With these [BP] labs, it's such a different environment to our other labs, like } \\
\text { Biochem that's so structured, you don't have any freedom to do what you } \\
\text { want. You feel a lot more motivated coming out of the lab to go home and } \\
\text { do your own personal study. I find that I write a lot less, but it has a lot } \\
\text { more meaning and it's better set out and a lot more images than the writing } \\
\text { (female Osteopathy student) } \\
\text { cine student) }\end{array}$ \\
\hline
\end{tabular}


Table 3 (continued)

\begin{tabular}{|c|c|c|}
\hline $\begin{array}{l}\text { Learning } \\
\text { strategy }\end{array}$ & Why this learning strategy works & Learning outcomes for students \\
\hline $\begin{array}{l}\text { Students } \\
\text { practically } \\
\text { apply } \\
\text { textbook } \\
\text { and other } \\
\text { didactic } \\
\text { knowledge } \\
\text { on a real } \\
\text { live person } \\
\text { by taking } \\
\text { time to } \\
\text { identify the } \\
\text { muscles, } \\
\text { tendons, } \\
\text { blood } \\
\text { vessels and } \\
\text { other SA } \\
\text { through } \\
\text { palpitating, } \\
\text { moving } \\
\text { and other } \\
\text { practical } \\
\text { classroom } \\
\text { aids, and } \\
\text { then using } \\
\text { colour } \\
\text { paints to } \\
\text { differenti- } \\
\text { ate the } \\
\text { various } \\
\text { anatomy }\end{array}$ & 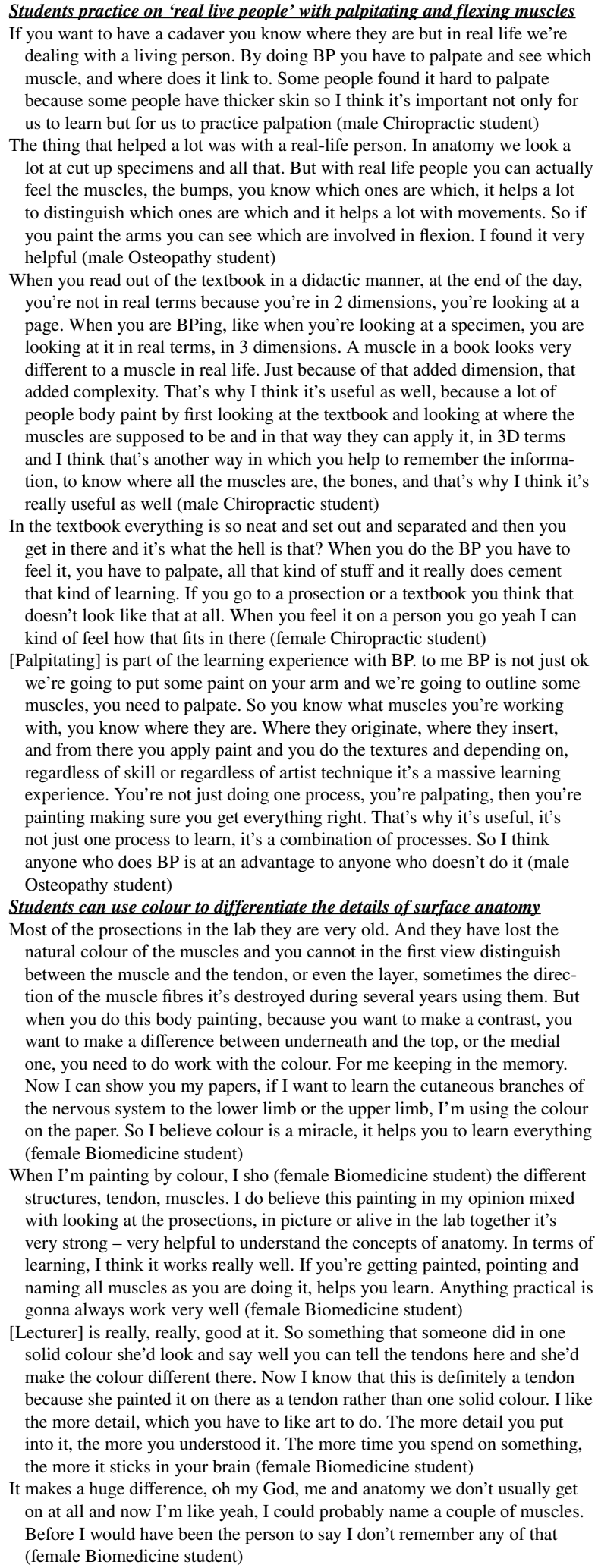 & 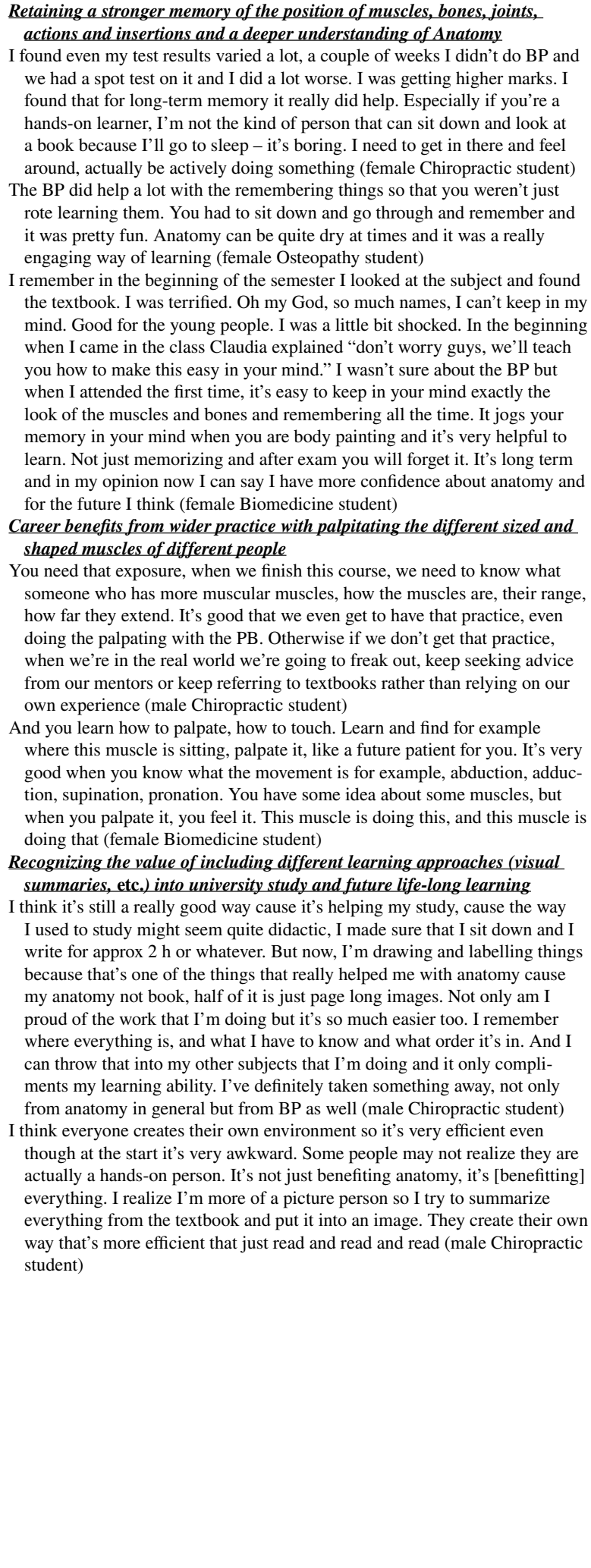 \\
\hline
\end{tabular}


Table 4 Summary of themes and comments made in three focus groups of Royal Melbourne Institute of Technology health science students $(n=13)$ regarding the potential barriers or caveats to their participation in Body Painting activities

\begin{tabular}{|c|c|}
\hline Theme & Potential barriers or caveats to this learning strategy \\
\hline $\begin{array}{l}\text { Not all student will participate in self-directed BP } \\
\text { activities, though more students will participate } \\
\text { over time }\end{array}$ & 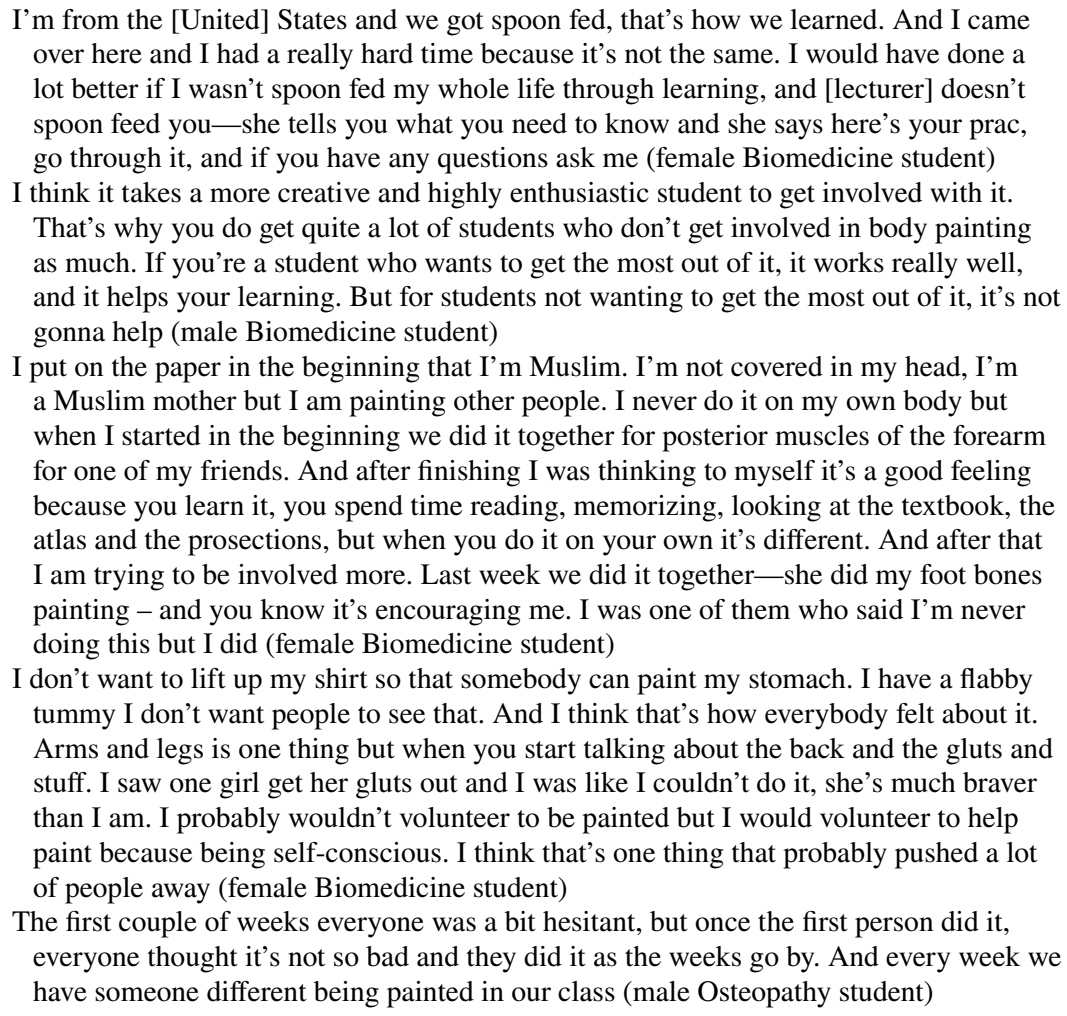 \\
\hline BP takes time to do & $\begin{array}{l}\text { I can paint, but I might paint badly, but I'll paint accurately. It might not be beautiful but } \\
\text { I know where they are. But to achieve the accuracy I have to know where they are and } \\
\text { how they work, what's the shape, how big, where's the position. Where's it located in } \\
\text { the arm, leg, wherever. This is very different from textbooks so we have to get some } \\
\text { time to get used to it (male Chiropractic student) }\end{array}$ \\
\hline BP works best as a supplementary activity & $\begin{array}{l}\text { BP was a fantastic thing to have but it was one of several good things in the [prac] room } \\
\text { (female Osteopathy student) } \\
\text { I think the important thing is that as long as it's not considered as an entire replacement, } \\
\text { but it's considered as a supplement. One week it might work for you to write stuff but } \\
\text { then next week you get to a different topic and you're trying to take sense of it, and it's } \\
\text { not working, so you need to look at it differently, which is where I think people get the } \\
\text { most out of BP (male Chiropractic student) }\end{array}$ \\
\hline
\end{tabular}

The focus group discussion described key aspects for why BP assisted students to learn SA. In summary, BP was a group-based, self-directed learning approach supported by tutors and the lecturer. This self-directed learning, over time, led students to more strongly engage with anatomy course content, while learning with other students and tutors helped identify and confirm the correct anatomical knowledge. In addition, BP required students to practically apply textbook and other didactic knowledge on a real live person by taking the time to identify the muscles, tendons, blood vessels, and other SA through palpitating, movements, and other practical classroom aids, and then using markers and color paints to differentiate the various anatomy - "learning by doing".

One student commented:
The way I used to study might seem quite didactic. I made sure that I sit down and I write for approximately 2 hours or whatever. But now, I'm drawing and labelling things because that's one of the things that really helped me with anatomy. 'Cause my anatomy book, half of it is just page long images. Not only am I proud of the work that I'm doing, but it's so much easier too. I remember where everything is, and what I have to know and what order it's in. And I can throw that into my other subjects that I'm doing and it compliments my learning ability. I've definitely taken something away, not only from anatomy in general but from BP as well (male Chiropractic student). 
Fig. 1 Body painting activities in anatomy practical classes. A, B Landmarking process where bones, outlines, and muscle fibers are initially drawn in using whiteboard markers. This was often the most educational part of the BP process. $\mathbf{C}, \mathbf{D}$, E Body painting carried out for all areas of musculoskeletal anatomy, shoulder, thigh, forearm, and by all cultural groups
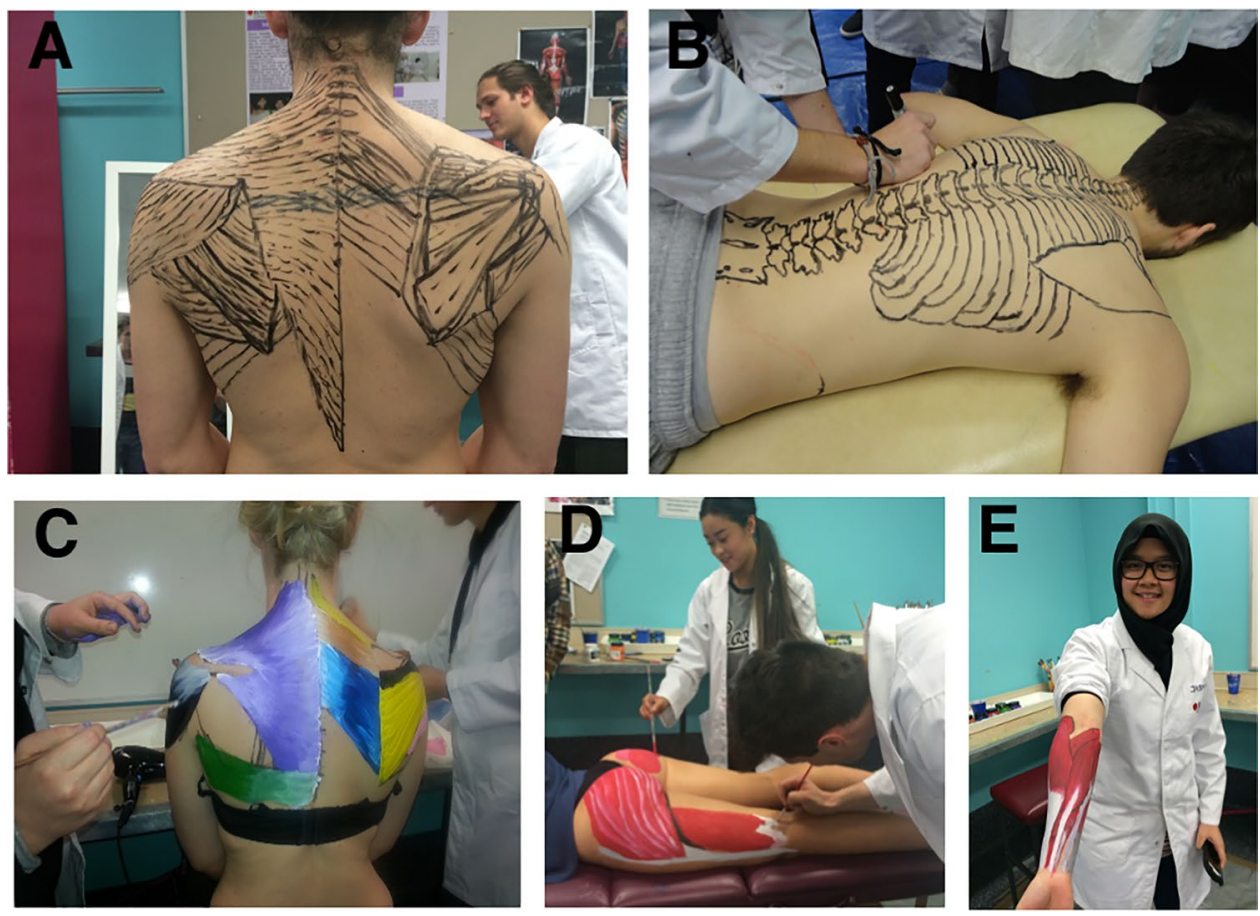

Another student commented:

It was nice having other people around, I wasn't the only one that didn't understand it. Having someone else talk it through with you, physically show you it, it really helped. It helps you learn, how to learn with other people (female Biomedicine student).
BP allowed students to learn surface anatomy on a living person, usually after first investigating with textbooks and cadavers, along with palpating the muscles and using color to differentiate the surface anatomy helping students to learn, understand, and remember. As a student commented:
Fig. 2 Body painting in anatomy classes and by professional groups. A, C Body painting was a group activity in each anatomy practical class. Students were proud to be photographed for the Facebook page at the end of each session. B Body painting by radiographers from Townsville Hospital. D, E The LA County Coroner being body painted at the British Institute of Embalming Conference in Melbourne, Australia 2016
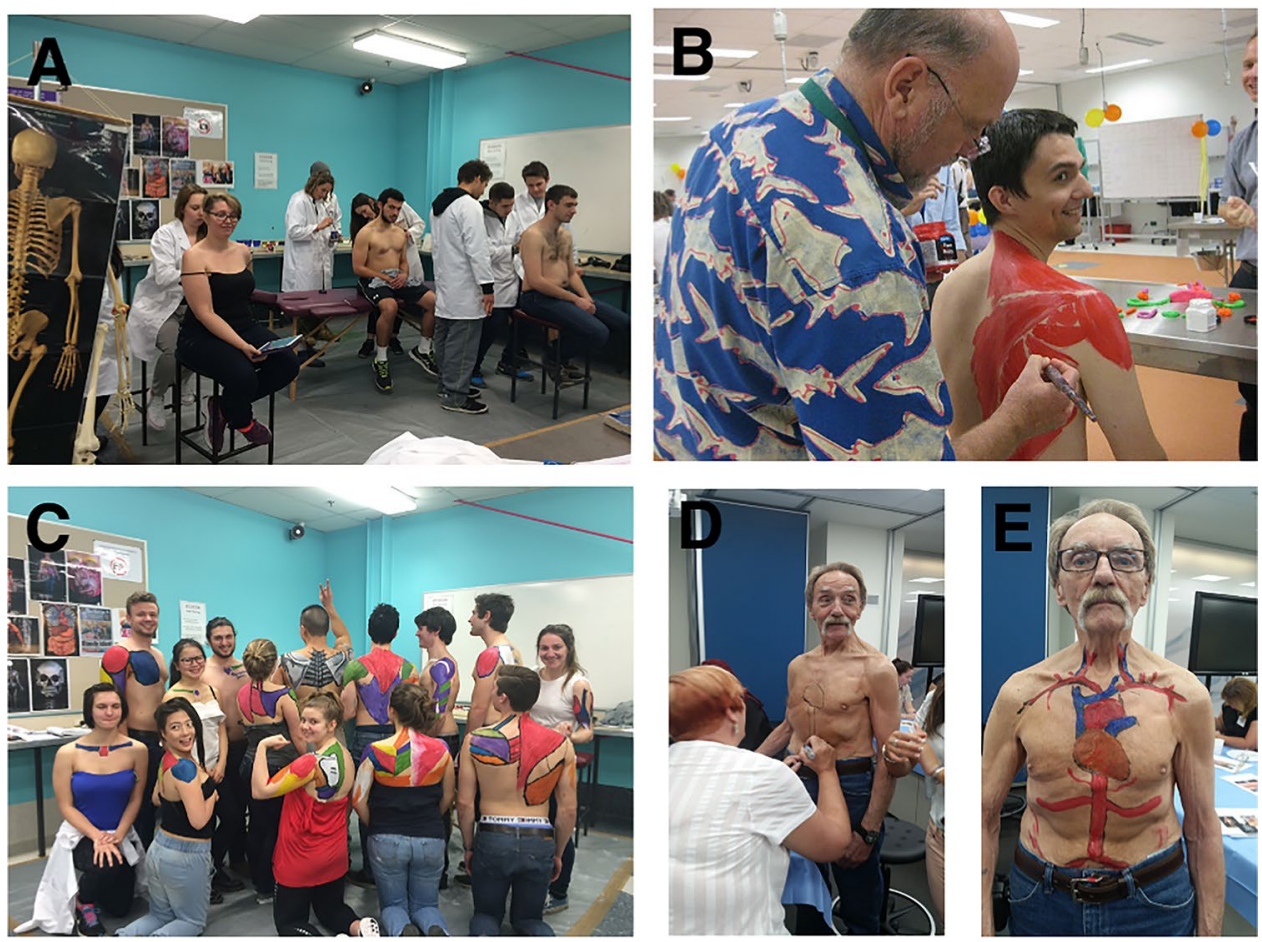
In the textbook everything is so neat and set out and separated and then you get in there and it's what the hell is that? When you do the BP you have to feel it, you have to palpate, all that kind of stuff, and it really does cement that kind of learning. If you go to a prosection or a textbook, you think that doesn't look like that at all. When you feel it on a person you go 'yeah, I can kind of feel how that fits in there' (female Chinese Medicine student).

BP also allowed students to practice palpitating different individuals, each with differences in their surface anatomy. With regard to palpitating the muscles, a student mentioned:

You need that exposure. When we finish this course, we need to know what someone who has more muscular muscles feels like, how the muscles are, their range, how far they extend. It's good that we even get to have that practice, even doing the palpating with the BP. Otherwise if we don't get that practice, when we're in the real world we're going to freak out, keep seeking advice from our mentors or keep referring to textbooks rather than relying on our own experience (male Chiropractic student).

Another student commented:

And you learn how to palpate, how to touch. Learn and find for example where this muscle is sitting, palpate it, like a future patient for you. It's very good when you know what the movement is for example, abduction, adduction, supination, pronation. You have some idea about some muscles, but when you palpate it, you feel it. This muscle is doing this, and this muscle is doing that (female Biomedicine student).

Thus, students appreciated working on living people as a way to understand and strengthen their anatomy knowledge relevant to their future professions.

The use of color was also a good tool for learning, understanding, and remembering. One student commented:

When I'm painting by colour, I show the different structures, tendon, muscles. I do believe this painting in my opinion mixed with looking at the prosections, in picture or alive in the lab together it's very strong - very helpful to understand the concepts of anatomy. And, in terms of learning, I think it works really well. If you're getting painted, pointing and naming all muscles as you are doing it, helps you learn (female Biomedicine student).

Another student commented:

[Lecturer] is really, really, good at it [surface anatomy]. So, something that someone did in one solid colour, she'd look and say 'well, you can tell the tendons here' and she'd make the colour different there. Now I know that this is definitely a tendon because she painted it on there as a tendon rather than one solid colour. I like the more detail, which you have to like art to do. The more detail you put into it, the more you understood it. The more time you spend on something, the more it sticks in your brain (male Biomedicine student).

This participation in BP led to students achieving learning benefits directly associated with the anatomy course - retaining a stronger memory of the position of bones, joints, muscles, actions, and insertions and a deeper understanding of anatomy - as well as longerterm benefits of wider practice with palpating the different sized and shaped bones and muscles of different people, and recognizing the value of including different learning approaches (visual summaries, tactile learning) into their university study and future life-long learning. These key aspects are summarized in Fig. 3, and a more detailed description of the key themes is provided in Table 3 along with those student comments which well capture the identified key themes, taken verbatim from the transcripts.

However, it was commonly observed that not all students participated in BP activities. The potential barriers or caveats to participation in BP activities were also explored in the focus groups, with these summarized in Table 4.

\section{Discussion}

This study provides both quantitative and qualitative data not previously available regarding the value and mechanisms by which BP assists student learning of surface anatomy. The findings show that the majority of students in this study, undertaken towards the end of the course, reported a preference to learn surface anatomy (SA) via self-directed, groupbased experiential learning activities, such as those involving $\mathrm{BP}$, and that almost three-quarters of the students reported BP helped them learn anatomy "quite a bit" or "very much".

This study supports the use of student-centered teaching and learning methods including flexible, experiential, and self-directed learning [35]. Student-centered teaching is a powerful approach that moves the focus from the teacher to the student, encouraging active, energized, and engaged learning. Other studies have also shown most students appear to prefer hands-on, group-based, practical teaching activities to learn anatomy [36, 37]. In addition, the teaching of surface and internal anatomy has previously found to have benefited from a range of experiential learning strategies: drawing [11, 38, 39]; radiology [40]; ultrasound imaging [41-43]; Web-based and virtual methods [41, 44, 45]; visual 
arts [46]; clay modelling, Play Doh, and white-boarding [14, 17, 39]; and BP [15, 17, 20-28]. The study findings and other associated literature suggest that adding BP activities with a significant level of experiential learning to anatomy practical sessions would complement the more traditional practical session approach involving individually focused examinations of laboratory prosections.

Students in the present study also reported high-level bonding and interaction with peers and tutors during BP activities, and that the $\mathrm{BP}$ activities provided motivation and enjoyment of anatomy learning. Peer learning was an important part of the BP experience for students in this studyas consistent with "Engagement Theory" — students were engaged in meaningful, collaborative learning activities involving peer interaction to achieve deep learning $[31,32]$. These study findings confirm those obtained in an earlier study at a regional Australian University [14, 17], showing the addition of BP activities significantly improved medical and health science students' engagement with teachers and peers to assist anatomy learning and long-term anatomy knowledge and understanding. It has been proposed that learning activities actively involving drawing of surface anatomy provide students an immediate enjoyment of anatomy; which in time lead to improved engagement and deep learning $[14,17,39]$. Enjoyable and fun anatomical learning activities are known to result in improved engagement, consistent with reports in both science [47] and education teaching [48].

The present study also identified the three key factors behind why many students believed BP activities helped them learn surface anatomy - (1) by helping students integrate textbook and other knowledge onto a real live person; (2) reach a deeper understanding of human surface anatomy; and (3) remember the muscles, bones, joints, and other aspects of surface anatomy. These key factors can be summarized as BP helping students to sequentially "learn the correct names and positions of surface anatomy on the human body" $\rightarrow$ "understand how the surface anatomy functions" $\rightarrow$ "remember the names and positions of the surface anatomy". This "learn" $\rightarrow$ "understand" $\rightarrow$ "remember" impact on students from the BP activities was also strongly represented in the qualitative findings.

Students reported the BP activities helped them learn the correct names and positions of surface anatomy on the human body because the activities were undertaken in friendly collaboration with the other students, tutors, and lecturers. The BP activities were often the first time students had experienced self-directed, group-based learning. The self-directed learning helped students actively and enthusiastically engage in their own learning — often using drawing and pictures to supplement the BP-while the group-based learning aspect with tutors and the lecturer present helped students learn correctly. Thus, the self-directed, friendly group collaboration created an engaged learning environment wherein students developed their skills in "learning how to learn" - that is, becoming more confident in undertaking self-directed learning, while the input from the other students, tutors and lecturers helped students learn the names, positions, and other aspects of human surface anatomy correctly.
Fig. 3 Summary of the key findings of focus groups with firstyear chiropractic, osteopathy, and Chinese medicine students and second-year biomedical science students to explore indepth the key factors underpinning how body painting helped them learn surface anatomy. Group-based, self-directed learning assisted students to consolidate anatomy learning, taking it from books and cadavers to living human beings, thus achieving development of physical examination skills, and long-term retention of anatomical knowledge

\section{Body Painting: Learning by Doing}
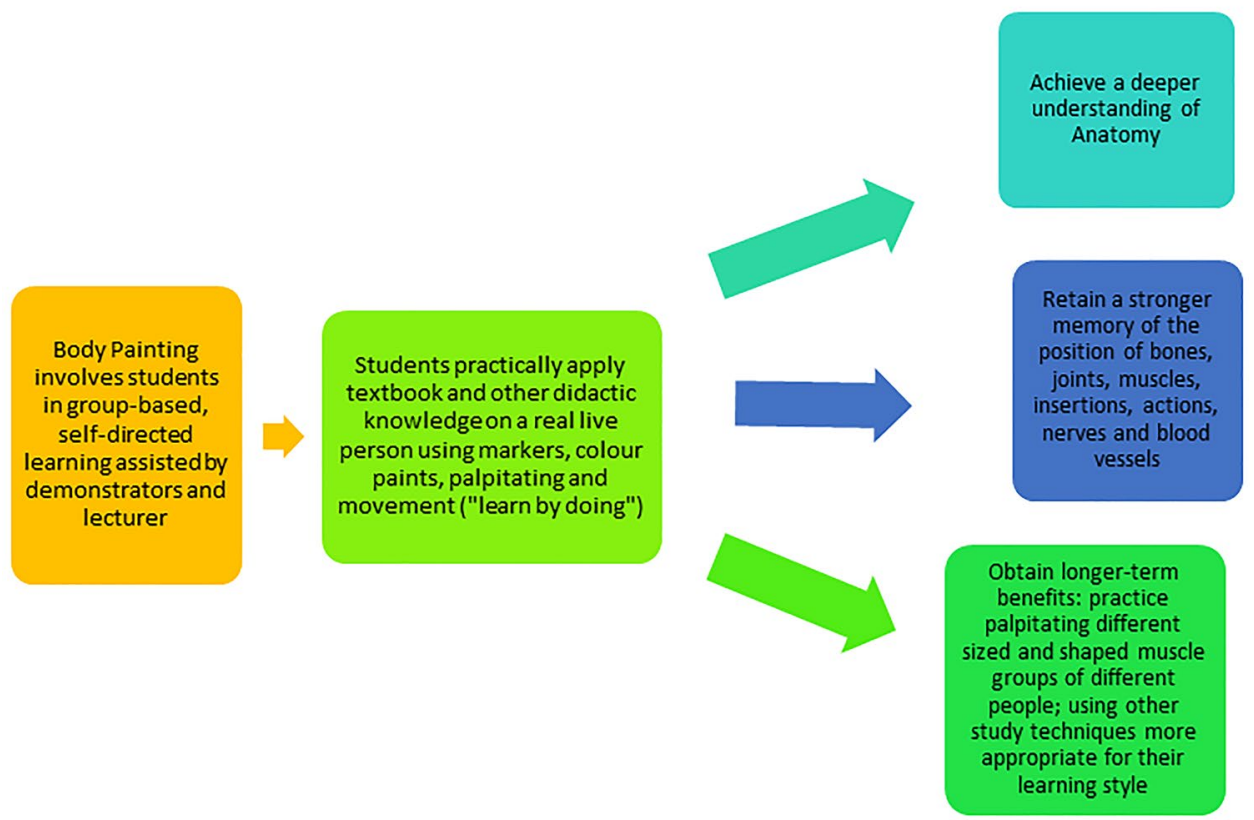
However, while BP was an engaging and productive learning exercise for participating students, it should be pointed out that not all students took part in this activity. Students who did not take part stated that they did not have time to dedicate to BP or that they did not feel confident in their drawing. Although BP is not an obligatory activity, future studies may examine the students that did not participate in BP to assess whether there may be approaches that could be employed to cater for their needs, although we acknowledge that BP will not suit all students and that other innovative approaches may be used instead [14, 17]. As anatomy practical classes were not obligatory, many students did not participate in BP as they were absent from many of the practical classes and did not participate in any practical activities. Interestingly, many students were not keen on the $\mathrm{BP}$ at the start of the semester; however, their views often changed significantly as the semester progressed and most of these students became active and enthusiastic participants in BP by the end of the course.

$\mathrm{BP}$ is not used at all universities as an instructional activity as it requires expert training of academic staff and tutors. The first author ran a Tutor Training Workshop twice a year to share this experience, and to ensure that tutors were trained to provide positive guidance to students in the process of BP, which often involved demonstration of palpation, landmarking, and painting techniques.

Body painting is a powerful and engaging tool for learning surface anatomy, and the quantitative and qualitative data obtained in this study are supportive of continuing its current use in anatomy education in Australia. Since 2010, body painting has been a key component in the anatomy curriculum for all teaching delivered by the first author at JCU, RMIT University, La Trobe University, and currently at CSU. At CSU, BP was used as part of the curriculum, even during the 2020 COVID-19 pandemic where anatomy teaching was delivered exclusively online. At CSU in 2020, anatomy was delivered effectively for a head and neck anatomy subject using pre-recorded videos combined with encouraging students to use innovative learning approaches, including body painting at home [49]. Students were receptive to the innovative learning challenge while in self-isolation and lockdown and several students shared pictures on the subject page of their body painting efforts on their children's faces [49].

\section{Limitations}

While the same survey instrument was used across three consecutive cohorts of Chinese medicine, biomedical science, and chiropractic and osteopathy students of the RMIT University to improve the reliability of findings, the survey itself was based on one used in a previous BP study at the JCU [14] that was not evaluated for validity or reliability.
In addition, it was not possible to use a comparative study design involving an intervention group of students who participated in BP activities versus a control group of students who did not, as Australian University research ethics committees do not allow this due to the possibility of students potentially being academically disadvantaged by not participating in BP activities. A further limitation of this study is that the data was self-reported, with students selfassessing how body painting assisted their recall and learning of anatomy week-to-week, over the semester, and leading into their exam study periods, that is, their "longer-term" memory. Therefore, the phrase "longer-term memory" used in this study only denotes memory and recall of anatomy over the semester and not into later years or future career. However, the focus group transcripts found students who participated in BP were able to clearly articulate that BP assisted them with their memory and recall of anatomy at least in the shorter term (over the duration of their course).

In addition, another issue of the data only being student self-report is that objective academic achievement scores were not also investigated. However, the first author anecdotally observed that students participating in extra-curricular BP projects were mostly the high achievers, tending to obtain distinctions (75-84\%) and high distinctions (85-100\%) in the subjects. Although final marks were not attributed unequivocally to participation in the BP projects, the high achievers were more likely to self-select into the BP student cohort, so it was inferred that participation in BP played some role in their success [50]. Future comparative longitudinal studies will therefore examine how students who participated in innovative anatomy teaching activities such as BP may have increased longer-term (6-12 months) knowledge and recall of anatomy teachings, as well as higher academic achievement scores, than students who did not participate in these activities.

\section{Conclusion}

This study provides novel and strong qualitative and quantitative evidence regarding the ways in which BP assists students to learn surface anatomy, evidence which advocates for the inclusion of BP strategies as a standard component of anatomy practical sessions. The inclusion of BP in anatomy practical classes can provide new perspectives towards teaching anatomy to students who prefer more hands-on, visual, kinesthetic, and/or group learning activities. For many students, BP activities provide a more engaging, motivating, inspiring, and enjoyable environment for student learning, and assists them to develop deeper understandings of how surface anatomy "works" in a human body, as well as better remembering of the names, positions, and other aspects of human surface anatomy. When used in conjunction with wet anatomy classes, the innovative BP approach appears 
to promote stronger learning engagement, more correct knowledge, deeper understanding of function, and longerterm memory retention of human surface anatomy. Thus, BP achieves a "learn" $\rightarrow$ "understand" $\rightarrow$ "remember" impact on students' learning of surface anatomy.

\section{Funding RMIT University STeLR Grant.}

\section{Declarations}

Ethical Approval RMIT Human Ethics Committee (ASEHAPP 16-13).

Informed Consent Implied consent was obtained from all individual participants included in the study by completion of the survey.

Conflict of Interest The authors declare no competing interests.

\section{References}

1. Ellis H. Teaching in the dissection room. Med Educ. 2001;14:149-51.

2. Aziz MA, McKenzie JC, Wilson JC, Cowie RJ, Ayenie SA, Dunn BK. The human cadaver in the age of biomedical informatics. Anat Rec. 2002;269:20-32.

3. Korf HW, Wicht H, Snipes RL, Timmermans JP, Paulsen F, Rune G, Baumgart-Vogt E. The dissection course - necessary and indispensable for teaching anatomy to medical students. Ann Anat. 2008;190:16-22.

4. Herle P, Saxena A. Contemporary teaching of anatomy in Australian medical schools: are we doing enough? ANZ J Surg. 2011;81:662-3.

5. Ghosh SK. Cadaveric dissection as an educational tool for anatomical sciences in the 21st century. Anat Sci Educ. 2017;10(3):286-99.

6. Patel SB, Mauro D, Fenn J, Sharkey DR, Jones C. Is dissection the only way to learn anatomy? Thoughts from students at a non-dissecting based medical school. Perspect Med Educ. 2015;4(5):259-60.

7. Waterston D. Anatomy in the living model: a handbook for the study of the surface, movements and mechanics of the human body and for the surface projection of the viscera, etc. 1st ed. London, UK: Hodder and Stoughton, Ltd.; 1931.

8. Kuhlenbeck H. Teaching of "living anatomy." J Assoc Am Med Coll. 1939;14:319-22.

9. Collett T, Kirvell D, Nakorn A, McLachlan JC. The role of living models in the teaching of surface anatomy: some experiences from a UK Medical School. Med Teach. 2009;31:e90-6.

10. Standring S. Evidence-based surface anatomy. Clin Anat. 2012;25:813-5.

11. Azer SA. Learning surface anatomy: which learning approach is effective in an integrated PBL curriculum? Med Teach. 2011;33:78-80.

12. Azer SA. The place of surface anatomy in the medical literature and undergraduate anatomy textbooks. Anat Sci Educ. 2013;6:415-32.

13. Bergman EM, Sieben JM, Smailbegovic I, de Bruin AB, Scherpbier AJ, van der Vleuten CP. Constructive, collaborative, contextual, and self-directed learning in surface anatomy education. Anat Sci Educ. 2013;6:114-24.

14. Diaz CM, Woolley T. Engaging multidisciplinary first year students to learn anatomy via stimulating teaching and active, experiential learning approaches. Med Sci Educ. 2015;25:367-76.

15. Cookson NE, Aka JJ, Finn GM. An exploration of anatomists' views toward the use of body painting in anatomical and medical education: an international study. Anat Sci Educ. 2018;11(2):146-54.

16. Johnson EO, Charchanti AV, Troupis TG. Modernization of an anatomy class: from conceptualization to implementation. A case for integrated multimodal-multidisciplinary teaching. Anat Sci Educ. 2012;5:354-66.

17. Diaz CM. Innovation in anatomy teaching. In: Ganguly P, editor. Education in anatomical sciences. 1st ed. Hauppauge, NY: Nova Science Publishers; 2013. p. 155-73.

18. Kolb DA, Fry R. Towards an applied theory of experiential learning. In: Cooper $\mathrm{C}$ (Editor). Theories of group process. 1st Ed. London, UK: John Wiley and Sons Ltd. p. 33-57. 1975.

19. Fewster-Thuente L, Batteson TJ. Kolb's experiential learning theory as a theoretical underpinning for interprofessional education. J Allied Health. 2018;47(1):3-8.

20. Op den Akker JW, Bohnen A, Oudegeest WJ, Hillen B. Giving color to a new curriculum: bodypaint as a tool in medical education. Clin Anat. 2002;15:356-362.

21. McMenamin PG. Body painting as a tool in clinical anatomy teaching. Anat Sci Educ. 2008;1:139-44.

22. Finn GM. Twelve tips for running a successful body painting teaching session. Med Teach. 2010;32:887-90.

23. Finn GM, McLachlan JC. A qualitative study of student responses to body painting. Anat Sci Educ. 2010;3:33-8.

24. Finn GM. Using body painting and other art-based approaches to teach anatomy. In: Chan LK, Pawlina W, editors. Teaching anatomy: a practical guide. 1st ed. New York, NY: Springer International Publishing; 2015. p. 155-64.

25. Finn GM. Current perspectives on the role of body painting in medical education. Adv Med Educ Pract. 2018;9:701-6.

26. Nanjundaiah K, Chowdapurkar S. Body painting: A tool which can be used to teach surface anatomy. J Clin Diagn Res. 2012;6:1405-8.

27. Bennett $C$. Anatomic body painting: where visual art meets science. J Physician Assist Educ. 2014;25:52-4.

28. Jariyapong P, Punsawad C, Bunratsami S, Kongthong P. Body painting to promote self-active learning of hand anatomy for preclinical medical students. Med Educ Online. 2016;21:30833.

29. Lambert VA, Lambert CE. Qualitative descriptive research: an acceptable design. Pacific Rim Int J Nurs Res. 2012;16(4):255-6.

30. Bomia L, Beluzo L, Demeester D, Elander K, Johnson M, Sheldon B. The impact of teaching strategies on intrinsic motivation. 1st Ed. Champaign, IL: ERIC Institute of Education Sciences, U.S. Department of Education. 1997. p. 28.

31. Kearsley G, Schneiderman B. Engagement theory: a framework for technology-based teaching and learning. Educ Technol. 1998;38:20-3.

32. Kift S. Articulating a transition pedagogy to scaffold and to enhance the first year student learning experience in Australian higher education: final report for ALTC Senior Fellowship Program. 1st Ed. Strawberry Hills, NSW, Australia: Australian Learning and Teaching Council. 2009.

33. Sandelowski M. Sample size in qualitative research. Res Nurs Health. 1995;18(2):179-83.

34. Pearce N. Effect measures in prevalence studies. Environ Health Perspect. 2004;112:1047-50.

35. O'Neill G, McMahon T. Student-centred learning: what does it mean for students and lecturers? In: O'Neill, Moore, McMullin, editors. Emerging issues in the practice of university learning and teaching. AISHE. 2005.

36. Moxham BJ, Moxham SA. The relationships between attitudes, course aims and teaching methods for the teaching of gross anatomy in the medical curriculum. Eur J Anat. 2007;11:S19-30.

37. Anstey LM. "Applying anatomy to something I care about": authentic inquiry learning and student experiences of an inquiry project. Anat Sci Educ. 2017;10:538-48.

38. Clavert P, Bouchaib J, Duparc F, Kahn JL. A plea for the use of drawing in human anatomy teaching. Surg Radiol Anat. 2012;34:787-9.

39. Nicholson LL, Reed D, Chan C. An interactive, multi-modal anatomy workshop improves academic performance in the health sciences: a cohort study. BMC Med Educ. 2016;16:7. 
40. Collins JP. Modern approaches to teaching and learning anatomy. BMJ. 2008;337:a1310.

41. McLachlan JC, de Bere SR. How we teach anatomy without cadavers. Clin Teach. 2004;1:49-52.

42. Royer DF, Kessler R, Stowell JR. Evaluation of an innovative hands-on anatomy-centered ultrasound curriculum to supplement graduate gross anatomy education. Anat Sci Educ. 2017;10:348-62.

43. Walrod BJ, Schroeder A, Conroy MJ, Boucher LC, Bockbrader M, Way DP, McCarney KL, Hartz CA, Jonesco MA, Bahner DP. Does ultrasound-enhanced instruction of musculoskeletal anatomy improve physical examination skills of first-year medical students? J Ultrasound Med. 2018;37(1):225-32.

44. Moro C, Štromberga Z, Raikos A, Stirling A. The effectiveness of virtual and augmented reality in health sciences and medical anatomy. Anat Sci Educ. 2017;10:549-59.

45. Ozer MA, Govsa F, Bati AH. Web-based teaching video packages on anatomical education. Surg Radiol Anat. 2017;39:1253-61.
46. Bramstedt KA. The use of visual arts as a window to diagnosing medical pathologies. AMA J Ethics. 2016;18:843-54.

47. Hampden-Thompson G, Bennett J. Science teaching and learning activities and students' engagement in science. Int J Sci Educ. 2013;35:1325-43.

48. Al-Shara I. Learning and teaching between enjoyment and boredom as realized by the students: a survey from the educational field. Eur Sci J. 2015;11:146-68.

49. Diaz CM, Linden K, Solyali V. Novel and innovative approaches to teaching human anatomy classes in an online environment during a pandemic. Med Sci Educ. 2021; https://doi.org/10.1007/ s40670-021-01363-2.

50. Diaz CM. Beyond the classroom: inspiring medical and health science students to learn anatomy. 2021;(submitted).

Publisher's Note Springer Nature remains neutral with regard to jurisdictional claims in published maps and institutional affiliations. 